\title{
Endozoochory of large bryophyte fragments by waterbirds.
}

David M Wilkinson ${ }^{1,2}$, Adam Lovas-Kiss ${ }^{3}$, Des A. Callaghan ${ }^{4}$, Andy J. Green ${ }^{5}$

1. Natural Science and Psychology, Liverpool John Moores University, Bryom Street, Liverpool, L3 3AF, UK. (D.M.Wilkinson@ljmu.ac.uk).

2. School of Life Sciences, University of Lincoln, Joseph Banks Laboratories, Green Lane, Lincoln, LN6 7DL, UK.

3. Department of Botany, University of Debrecen, Debrecen Egyetem sq. 1, Debrecen 4032, Hungary

4. Bryophyte Surveys Ltd, 65 Belle Vue Road, Stroud, Gloucestershire, GL5 1PY, UK.

5. Estación Biológica de Doñana, EBD-CSIC, Américo Vespucio s/n, 41092 Sevilla, Spain

Dispersal is a fundamental requirement for all organisms, indeed theoretical arguments show that dispersal is still required even in a uniform and predictable environment, and it is obviously a key mechanism by which plants respond to climate change (Hamilton \& May, 1977; Huntley \& Webb, 1989). In bryophytes, spores provide an especially important means of dispersal (Glime, 2014; Porley \& Hodgetts, 2005), and are often small enough to potentially be moved between continents in the atmosphere (Wilkinson et al, 2012). However, waterbirds are also major vectors for a broad range of plant types (Green et al., 2016), and it is likely that bryophyte spores are dispersed by migratory waterbirds, both by epizoochory (external dispersal on plumage or feet) and endozoochory (internal dispersal after ingestion and survival of transit through the gut). Indeed, Proctor (1961) showed experimentally that spores of the liverwort Riella americana survive gut passage through Mallards (Anas platyrhynchos).

Spores are not the only potential units of dispersal. As bryophytes are totipotent, in principle a new plant can arise from any small fragment - even from a single cell (Porley \& Hodgetts, 2005). The potential for dispersal of such fragments was illustrated by Parsons et al (2007), who extracted and cultured numerous viable bryophyte fragments (including Acroprium sp.) from the faeces of the spectacled flying fox (Pteropus conspicillatus). These fragments were possibly ingested by the bats while grooming (Parsons et al, 2007). However, many migratory bird species could potentially move bryophyte fragments far greater distances than fruit bats. There is some evidence for ectozoochory of fragments by migratory waterbirds. Potentially viable Sphagnum leaf fragments and a Bryopsid leaf fragment were recovered from the plumage of American golden plover (Pluvialis dominica), semipalmated sandipiper (Calidris pusilla), and red phalarope (Phalaropus fulicarius; Lewis et al. 2014a), although importantly their viability was not confirmed. Long distance dispersal by these trans-equatorial migratory shorebirds has been proposed as the explanation for the bipolar biogeographical distributions of many bryophytes (Lewis et al. 2014a, 2014b). This is a potentially important mechanism given the difficulty in moving between hemispheres if relying on wind dispersal (Wilkinson et al, 2012). However, we are unaware of any record in the literature of 
endozoochory of bryophyte fragments being internally transported in birds. Here we describe evidence of endozoochory from a study of the role of waterbirds in plant dispersal in North West England during 2016.

Fresh faeces were collected after flushing monospecific groups of waterbirds that were resting on the land, with each sample corresponding to a different individual. Faecal samples were visually inspected in the field, removing any soil or plant fragments adhering to the outside of the faeces, before being placed in a zip-lock bag then transported back to the laboratory, where they were kept in a fridge until processing (with a delay of up to one week). All the moss fragments described below looked potentially viable (i.e. they were still green), and came from within the dropping. They were extracted after sieving using deionised water and a $125 \mu \mathrm{m}$ mesh, followed by examination of material under a binocular microscope. The sieve size and low magnification means that propagules $<100 \mu \mathrm{m}$ in diameter (such as those recorded by Lewis et al. 2014a) were not quantified. Large moss fragments were placed on non-nutrient agar in Petri dishes to attempt to confirm viability.

Fragments were recovered from three different locations. Five samples of Mallard faeces were

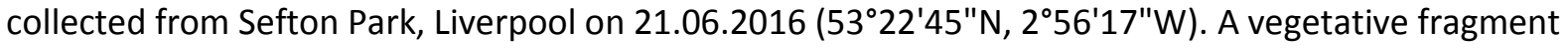
of moss was extracted from one sample but it failed to grow on agar. Twelve samples of mallard faeces were collected from Fell Foot, Lake Windermere (Fig. 1), in the English Lake District on 26.06.2016 $\left(54^{\circ} 16^{\prime} 32^{\prime \prime} \mathrm{N}, 2^{\circ} 57^{\prime} 9^{\prime \prime} \mathrm{W}\right)$. Vegetative fragments of moss were extracted from 4 samples (with a total of 5 fragments). All the fragments were placed on agar on 30.06.2016. One of these fragments grew, proving viability, and was maintained for six weeks. This moss was identified as Didymodon insulanus (Fig. 1), a common moss in the region and one often found at lowland lake margins, especially on concrete and brickwork, as indeed was the case at this site. This demonstrates not only that viable-looking fragments can be recovered from bird faeces, but that at least some of these fragments are able to grow into new plants.

In addition, 37 samples of Lapwing (Vanellus vanellus) faeces were collected from Budworth Mere, Cheshire $\left(53^{\circ} 17^{\prime} 21^{\prime \prime} \mathrm{N}, 2^{\circ} 31^{\prime} 11^{\prime \prime} \mathrm{W}\right)$, on 14.07.2016. A moss fragment was extracted from one sample, but failed to grow on agar. In total, over this time period in our wider study we looked at 430 faecal samples, collected from 10 species of waterbirds, but no other samples were observed to contain large moss fragments. While the mallards may have deliberately ingested moss while feeding, in the case of the lapwing the moss may have been accidently ingested, as this species mainly feeds on ground-living invertebrates (Cramp \& Simmons, 1983). Bryophytes have previously been recorded as food items for dabbling ducks (Owens 1972), diving ducks (Bartonek \& Murdy 1970) and especially migratory geese (Fox et al. 2006, Stech et al. 2011).

Given that birds in general, and waterbirds in particular, can fly long distances and often have high population sizes (e.g. there are around 4,500,000 Mallards in North-West Europe, Wetlands International, 2016) they are potentially important dispersers of bryophyte propagules both by endozoochory and ectozoochory - be these spores or vegetative fragments as described in this paper. Birds that migrate long distances in a short time, such as geese and other waterbirds which breed in the Arctic but overwinter in Britain - are likely to be particularly important bryophyte vectors. Given the high abundance of waterbirds it is likely that large numbers of viable vegetative fragments are moved around in this way, as previously estimated for dispersal of angiosperm seeds (Soons et al. 2016). Co-dispersal of other organisms by vertebrates is an area in need of far greater 
investigation (Tesson et al. 2016), as indicated by the fact that the first record of endozoochory of bryophyte fragments by birds has not been published until the $21^{\text {st }}$ Century!

\section{Acknowledgements}

AJG was supported by a mobility grant (PR2015-00049) from the Spanish Ministry of Education, Culture and Sport. ALK was supported by the Tempus Public Foundation. Both AJG and ALK carried out this work during visits to the School of Natural Science and Psychology at Liverpool John Moores University.

\section{References.}

Bartonek, J. C., \& Murdy, H. W. 1970. Summer foods of lesser scaup in subarctic taiga. Arctic 23: 3544.

Cramp, S. \& Simmons, K.E.L. (eds) 1982. The birds of the Western Palearctic, Vol. III. Oxford: Oxford University Press.

Fox, A. D., Francis, I. S., \&Bergersen, E. 2006. Diet and habitat use of Svalbard Pink-footed Geese Anser brachyrhynchus during arrival and pre-breeding periods in Adventdalen. Ardea, 94: 691-699.

Glime, J. M. 2014. Adaptive Strategies: Vegetative vs Sexual Diaspores. Chapter 4-7. In: Glime, J. M. Bryophyte Ecology. Volume 1.4-7-1 Physiological Ecology. Ebook sponsored by Michigan Technological University and the International Association of Bryologists. http://www.bryoecol.mtu.edu

Green, A.J., Brochet, A.L., Kleyheeg, E., Soons, M.B. 2016. Dispersal of plants by waterbirds. Pp 147195 In: Why birds matter: Avian Ecological Function and Ecosystem Services. Eds. C.H.Şekercioğlu, D.G. Wenny, C.J. Whelan. University of Chicago Press.

Hamilton, W.D. \& May, R.M.1977.Dispersal in stable habitats. Nature 269: 578-581.

Huntley, B. \& Webb III, T. 1989. Migration: species' response to climatic variations caused by changes in the earth's orbit. Journal of Biogeography 16: 5-19.

Lewis, L.R., Behling, E., Gousse, H., Qian, E., Elphick, C.S., Lamarre, J.F., Bety, J., Liebezeit, J., Rozzi, R. \& Goffinet, B. 2014.First evidence of bryophyte diaspores in the plumage of transequatorial migrant birds. Peerj 2:e424 https://doi.org/10.7717/peeri.424

Lewis, L.R., Rozzi, R. \& Goffinet, B. 2014. Direct long-distance dispersal shapes a New World amphitropical disjunction in the dispersal-limited dung moss Tetraplodon (Bryopsida: Splachnaceae). Journal of Biogeography, 41: 2385-2395.

Moss, B. 2015. Lakes, Loughs and Lochs. London: Collins.

Owens, A. B. 1972. Bryophytes and lichens of the Chesapeake Bay.Chesapeake Science, 13, S85-S86. 
Parsons, J.G., Cairns, A., Johnson, C.N., Robson, S.K.A., Shilton, L.A. \& Westcott, D.A. 2007.

Bryophyte dispersal by flying foxes: a novel discovery. Oecologia 152: 112-114.

Porley, R. \& Hodgetts, N. 2005. Mosses and Liverworts. London: Collins.

Proctor, V.W. 1961. Dispersal of Riella spores by waterfowl. Bryologist, 64: 58-61.

Soons, M., Brochet, A.L., Kleyheeg, E., Green, A.J. 2016.Seed dispersal by dabbling ducks: an overlooked dispersal pathway for a broad spectrum of plant species. Journal of Ecology 104:443-455

Stech, M., Kolvoort, E., Loonen, M. J. J. E., Vrieling, K., \& Kruijer, J. D. 2011. Bryophyte DNA sequences from faeces of an arctic herbivore, barnacle goose (Brantaleucopsis). Molecular Ecology Resources, 11: 404-408.

Tesson, S.V.M., Okamura, B., Dudaniec, R.Y., Vyverman, W., Löndahl, J., Rushing, C., Valentini, A., Green, A.J. 2016. Integrating micro and macro-organism dispersal: modes, techniques and challenges with particular focus on co-dispersal. Ecoscience 22: 109-124

Wetlands International 2016. "Waterbird Population Estimates". Retrieved from wpe.wetlands.org on Wednesday 14 Sep 2016

Wilkinson, D.M., Koumoutsaris, S., Mitchell, E.A.D. \&Bey, I. 2012. Modelling the effect of size on the aerial dispersal of microorganisms.Journal of Biogeography 39: 89-97.

Fig caption.

Fig 1a. Didymondon insulanus fragment from Fell Foot growing on agar. 


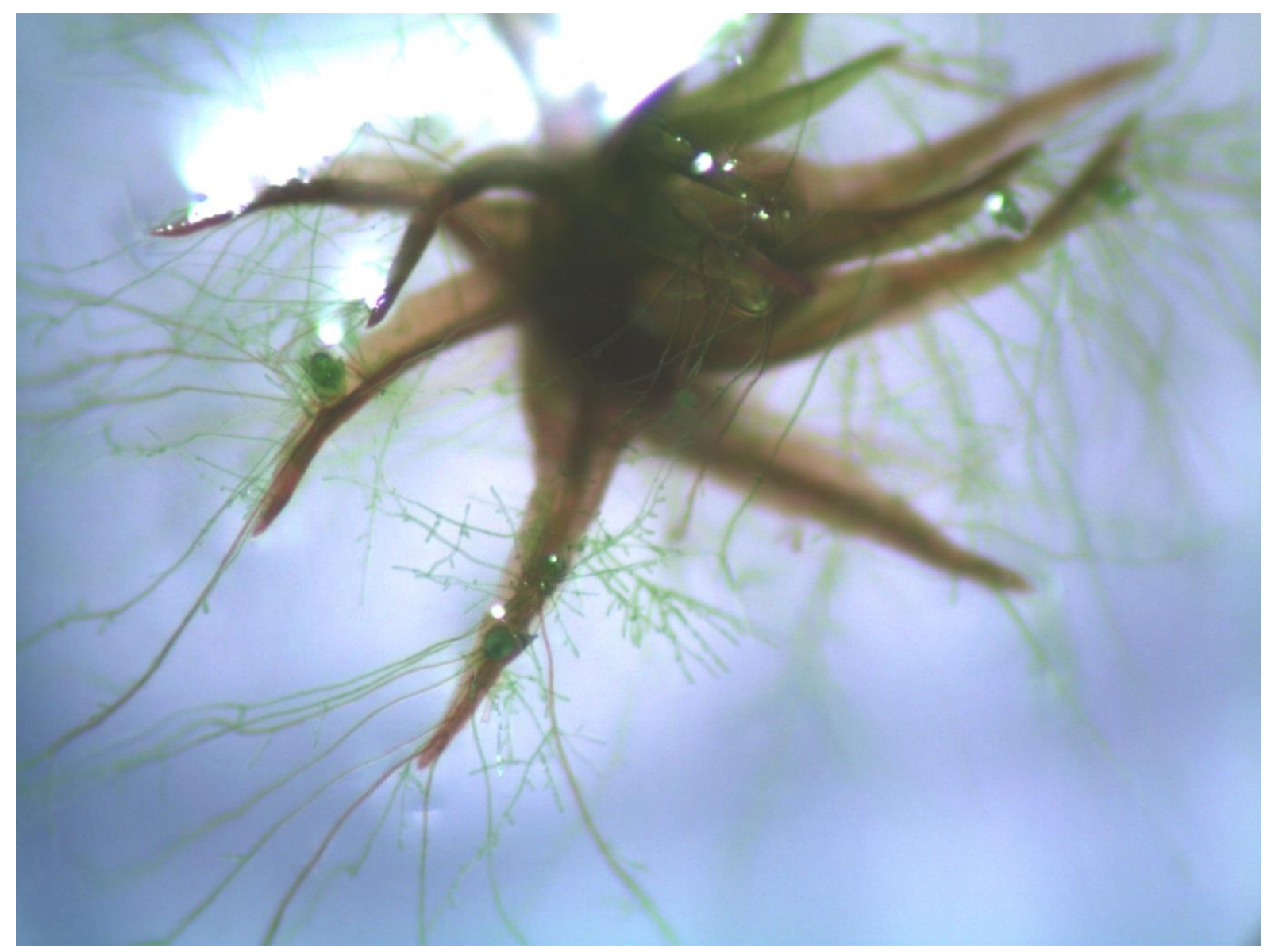

Fig $1 b$. The site at Fell Foot on Lake Windermere from which the mallard faeces containing $D$. insulanus were collected. Several moss species, including this one, are growing on the wall at the edge of the lake. Windermere is the most human influenced of the many lakes in the English Lake District and one of the most well studied lakes in the world, with a freshwater biology laboratory being opened on the lake shore in 1931 (Moss, 2015). 


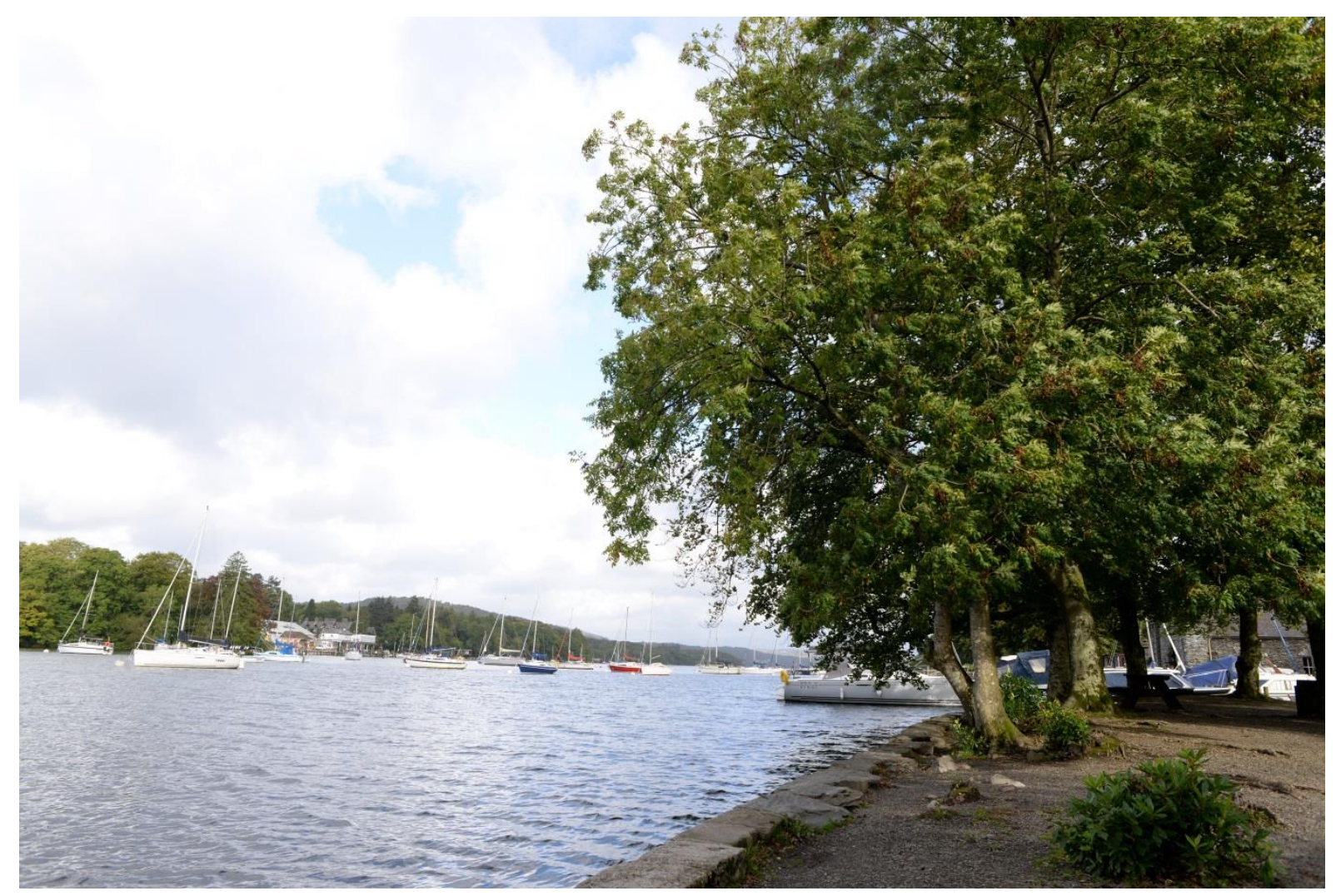

